(C) [2009] IEEE. Reprinted, with permission, from Guo, Youguang; Zhu, Jianguo; Dorrell, David; Lu, Hai Yan; Wang, Yi. 2009, 'Development of a Claw Pole Permanent Magnet Motor with a Molded Low-Density Soft Magnetic Composite Stator Core', Proceedings of IEEE Energy Conversion Conference \& Expo, pp. 294301. This material is posted here with permission of the IEEE. Such permission of the IEEE does not in any way imply IEEE endorsement of any of the University of Technology, Sydney's products or services. Internal or personal use of this material is permitted. However, permission to reprint/republish this material for advertising or promotional purposes or for creating new collective works for resale or redistribution must be obtained from the IEEE by writing to pubs-permissions@ieee.org. By choosing to view this document, you agree to all provisions of the copyright laws protecting it. 


\title{
Development of a Claw Pole Permanent Magnet Motor with a Molded Low-Density Soft Magnetic Composite Stator Core
}

\author{
Youguang Guo, Jianguo Zhu, David Dorrell, Haiyan Lu, and Yi Wang \\ Faculty of Engineering and Information Technology \\ University of Technology Sydney \\ 1 Broadway, PO Box 123, NSW 2007, Australia \\ youguang@eng.uts.edu.cu, joe@eng.uts.edu.au, david.dorrell@eng.uts.edu.au, helenlu@it.uts.edu.au, yiwang@eng.uts.edu.au
}

\begin{abstract}
SMC (soft magnetic composite) materials and SMC electrical machines have undergone significant development in the past decade. For the molding of the SMC core, if a high productivity low pressure press is used, the manufacturing cost can be dramatically reduced. However, the magnetic properties of the SMC core and the machine performance are highly dependant on the mass density of the core. This paper presents the development of a claw pole permanent magnet motor with a low mass density SMC stator core molded at low pressure which can replace the existing single phase induction motor in a dish washer pump. The developed SMC motor has been prototyped and tested. Both the parameter computation and performance prediction are validated by the experimental results. These show that the low mass density SMC core is suitable for low cost mass production of SMC electrical machines.
\end{abstract}

Index Terms-Claw pole motor; Low pressure molding; Magnetic field finite element analysis; Molded core; Phase variable model; Permanent magnet motor; Soft magnetic composite (SMC).

\section{INTRODUCTION}

Soft magnetic composite (SMC) materials have many unique properties. These properties include good design flexibility due to magnetic isotropy, very low eddy current characteristics because of the particle coating, and high potential for low-cost mass production through the powder metallurgical molding technique. Their use in electrical machine manufacture has undergone significant development in the past decade, and the results are very promising [1]. A large amount of research has been conducted by various researchers on designing and prototyping various types of electrical machine. These studies focus on the axial field permanent magnet (PM) machine [2]-[6], claw pole motor [7]-[10], transverse flux motor [11]-[13], hybrid axial and radial flux motor [14], PM radial field servo motor [15]-[16], DC motor [17], universal motor [18]-[19], induction motor [20], and switched reluctance motor [21]. They covered a variety of applications. Among these machines, the most significant types are the claw pole and transverse flux motors which feature complex structures and 3-D flux paths [22][23]. These features mean that it is difficult to use laminated steel so that SMC material appears to be an ideal substitute. The main constraint of steel laminations, i.e., the magnetic flux must flow within a 2-D lamination plane, is then removed. This offers greater design flexibility for exploiting novel-structure electrical machines, which may lead to improved performance and new applications.

However, SMC materials do have disadvantages. They have low magnetic permeability so that most of the SMC machines that have been developed are PM machines which have high magnet thickness. Hence the magnetic circuit is not very sensitive to the permeability of the core. Because the magnets have a permeability which is close to air the magnet reluctances dominate the magnetic circuit.

Most of the SMC motor prototypes investigated so far used the iron cores cut from existing pre-forms which were previously compacted with high pressure in a simple shape mold such as cylinder or bar. This technique might be appropriate for prototyping but not suitable for mass production because of the cost issue. Furthermore, the cutting process may significantly reduce the magnetic and mechanical properties of the SMC core. SMC is brittle so that in core production it is better to use a molding technique rather than machining a pre-formed sample. Some papers have addressed the molding of parts, i.e., a modular technique [24]-[25], but this still needs a large number of costly pressing and assembly stages. The ideal process should be that the core is pressed in one single step and that the coils can be easily fitted.

In commercial production, the manufacturing cost of the SMC motor can be dramatically reduced if a highproductivity low-pressure press is used in the molding. However, the magnetic properties of SMC material, and hence the motor performance, are very dependant on the mass density of the core. Therefore careful designing is necessary to obtain a good compromise between the molded core density and the machine performance.

To investigate the industrial "production-ready" products, the authors recently developed techniques for designing and prototyping PM motors with low-density molded SMC cores [26]. This paper further reports on the development of the claw pole PM SMC motor which could replace an existing single phase induction motor in a dish washer pump. A mold for pressing the SMC claw pole disk was designed and fabricated. SMC cores were compacted at two different pressures and the corresponding magnetic properties were measured and compared. The lower mass density core was used in the development of an SMC motor. Finite element 
magnetic field analysis was carried out for accurate calculation of the key motor parameters, such as winding flux, back-EMF, winding inductance and core loss. An improved phase-variable model was developed in Simulink for the prediction of motor performance.

A prototype was fabricated with the low-density molded SMC cores, and tested to validate the motor parameter computation and performance analysis. The theoretical analyses and experimental results illustrated that the lowdensity molded SMC core is suitable for mass production.

\section{Molded SMC CORE AND Motor PRototype}

As described in the last section, SMC is very suitable for developing complex-structured PM motors because of its unique magnetic and mechanical properties. This paper describes the development of a three-phase three-stack permanent magnet claw pole motor with SMC stator core which takes advantage of these unique properties. The conventional machine has a torque output which is proportional to the product of the air-gap magnetic flux and the electric loading, and is not very salient, even for an internal PM machine. The claw pole machine is highly salient so that it is very torque dense with high pole number (if magnetic saturation and leakage is ignored). Therefore, the claw pole motor usually has a large number of poles. Here, the claw pole motor is chosen to have 12 poles so that an excitation frequency of $300 \mathrm{~Hz}$ is required for a synchronous speed of $3000 \mathrm{rpm}$. The $300 \mathrm{~Hz}$ frequency is not unrealistically high for SMC material [22]-[23]. The low eddy current loss property due to the coated insulated particles allows the machine to operate at higher frequency, resulting in smaller size and weight for a given output.

The motor is designed to replace an existing induction motor for a dish washer pump, so the major dimensions (e.g. outer diameter and overall axial length) should be within the available space and deliver the same output. Fig. 1 shows the SMC claw pole disks after compaction in a mold with a single step press (no further machining required). Fig. 2 shows the assembled 3 phase stator core. Each phase consists of two disks with one concentrated axially-orientated global (i.e., spanning all poles) coil in between each molded disk. The simple structure allows a very high fill factor to be achieved. The stator is formed by stacking three phases axially with a circumferential spatial shift of $120^{\circ}$ electrical from each other. The major geometrical parameters are: stator inner diameter $=43 \mathrm{~mm}$, stator outer diameter $=67 \mathrm{~mm}$, effective axial length $=55 \mathrm{~mm}$, and air-gap length $=1 \mathrm{~mm}$. $12 \mathrm{NdFeB}$ magnets with dimensions of $55 \times 6.7 \times 3 \mathrm{~mm}^{3}$ are mounted on the surface of a mild steel rotor. The motor is designed to operate at $3000 \mathrm{rpm}$, delivering $60 \mathrm{~W}$ of mechanical power.

The stator core disks were compacted in a mold with a pressure of 20 ton force (about $179 \mathrm{MPa}$ ) or 100 ton force (895 MPa). This is slightly higher than $800 \mathrm{MPa}$, which is the nominal pressure for the SMC material [27]. The average mass densities are $5.8 \mathrm{~g} / \mathrm{cm}^{3}$ and $7.2 \mathrm{~g} / \mathrm{cm}^{3}$, respectively. As shown in Fig. 3, the measured B-H curve of the $5.8 \mathrm{~g} / \mathrm{cm}^{3}$ core is much lower than that of the $7.2 \mathrm{~g} / \mathrm{cm}^{3}$ core. However, the low density cores can be compacted at lower pressure, which yields much higher productivity compared to the higher density cores. This can be attractive for industry application. In this paper, the $5.8 \mathrm{~g} / \mathrm{cm}^{3}$ molded SMC core is used to fabricate the machine.

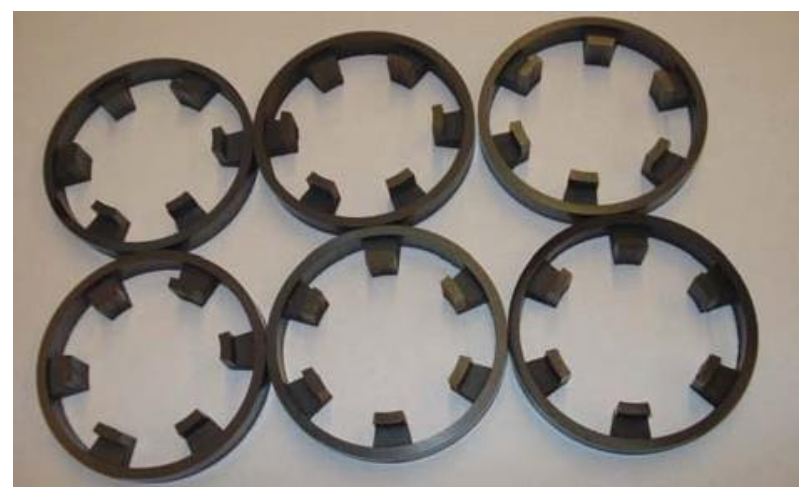

Fig. 1. Six Molded SMC claw pole disks for the motor stator core.

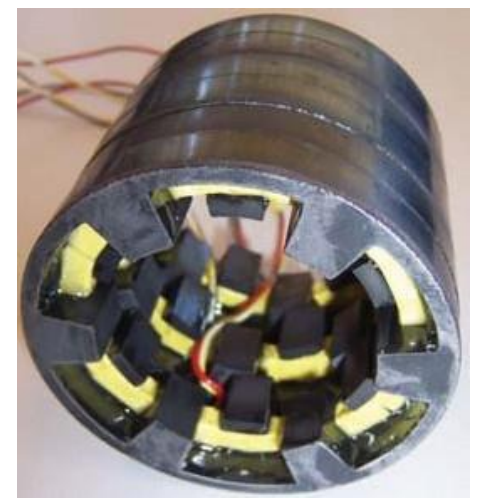

Fig. 2. Stator of a 3-phase claw pole motor

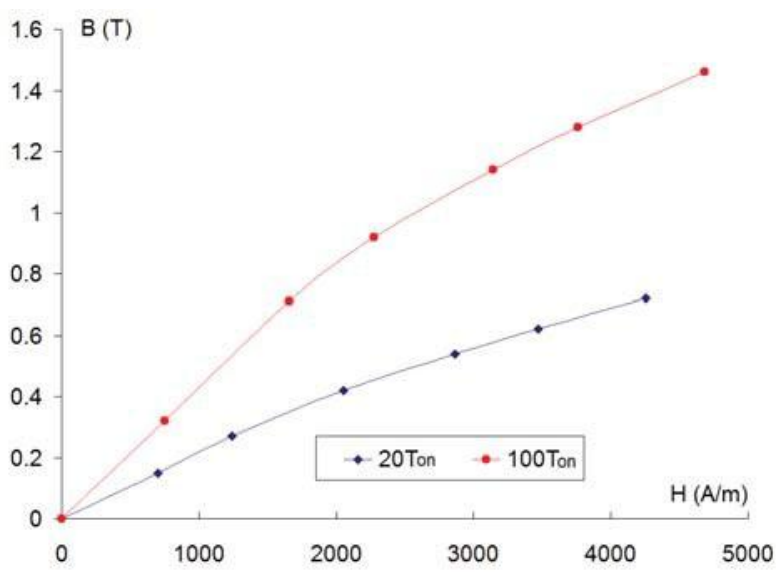

Fig. 3. Measured B-H curves of compacted SMC cores with pressure of 20 ton and 100 ton 


\section{Parameter Computation AND Performance ANALYSIS}

\section{A. Magnetic Field Finite Element Analysis and Parameter Computation}

Due to the complex structure and 3-D magnetic flux path of the claw pole motor, a 3-D numerical analysis of the magnetic field by, for example, finite element analysis is necessary to accurately determine the magnetic field distribution and major parameters. Structural symmetry means that only a pole region is needed for the field analysis, as shown in Fig. 4(a). On the two radial boundary surfaces, the scalar magnetic potentials should obey the following halfperiodical boundary conditions:

$$
\phi_{\mathrm{m}}(\mathrm{r}, \theta, \mathrm{z})=-\phi_{\mathrm{m}}(\mathrm{r}, \theta+\Delta \theta,-\mathrm{z})
$$

where $\Delta \theta=30^{\circ}$ is the angle of one pole pitch.

The conditions for magnetic flux density at the two boundary planes are:

$$
\begin{array}{r}
\mathrm{B}_{\mathrm{r}}(\mathrm{r}, \theta, \mathrm{z})=-\mathrm{B}_{\mathrm{r}}(\mathrm{r}, \theta+\Delta \theta,-\mathrm{z}) \\
\mathrm{B}_{\theta}(\mathrm{r}, \theta, \mathrm{z})=-\mathrm{B}_{\theta}(\mathrm{r}, \theta+\Delta \theta,-\mathrm{z}) \\
\mathrm{B}_{\mathrm{z}}(\mathrm{r}, \theta, \mathrm{z})=\mathrm{B}_{\mathrm{z}}(\mathrm{r}, \theta+\Delta \theta,-\mathrm{z})
\end{array}
$$

Fig. 4(b) illustrates the magnetic flux density vector plot at no-load and $\theta=0^{\circ}$ for the arrangement shown in Fig. 4(a). The claw poles face rotor magnets so that the main magnetic circuit has the lowest magnetic reluctance and the stator winding has maximum magnetic flux linkage. It can be seen that the major magnetic flux flows along a 3-D path, i.e. starting from the north pole of a rotor PM, radially passing across the air-gap to enter one claw pole, flowing into the SMC stator core (mainly axially in the claw pole, radially in the side wall, and circumferentially in the yoke), radially passing across the air-gap again into the south pole of another rotor PM, and finally through the mild steel rotor yoke to form a closed loop. It can also be found that a considerable amount of flux leakage exists between the side and end surfaces of the claw poles of the two separated disks. Considerable attention should be paid in the design stage to the reduction of the flux leakage.

From the no-load magnetic field distribution, a number of major motor parameters can be determined. For example, Fig. 5 plots the computed waveform of the flux linkage of one phase winding with the rotor PMs. This was obtained by calculating the flux at different rotor positions, e.g., by rotating the rotor magnets for one pole pitch in 24 steps. To reduce the computation error caused by meshing, separate fixed meshes are created for the stator and rotor parts and then merged in the middle of the air-gap when the rotor moves to a new position. It can be seen that the flux waveform is almost sinusoidal. (a)

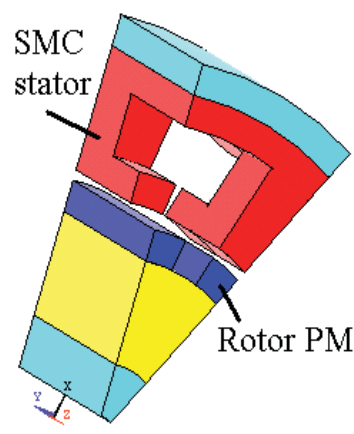

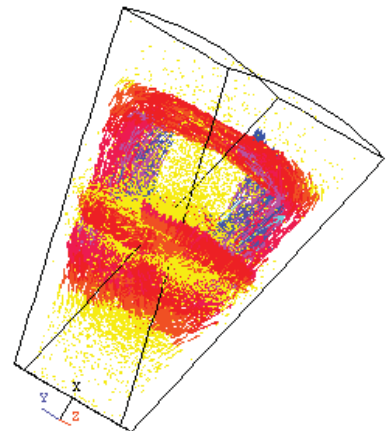

(b)
Fig. 4. Flux density vector plot at no-load

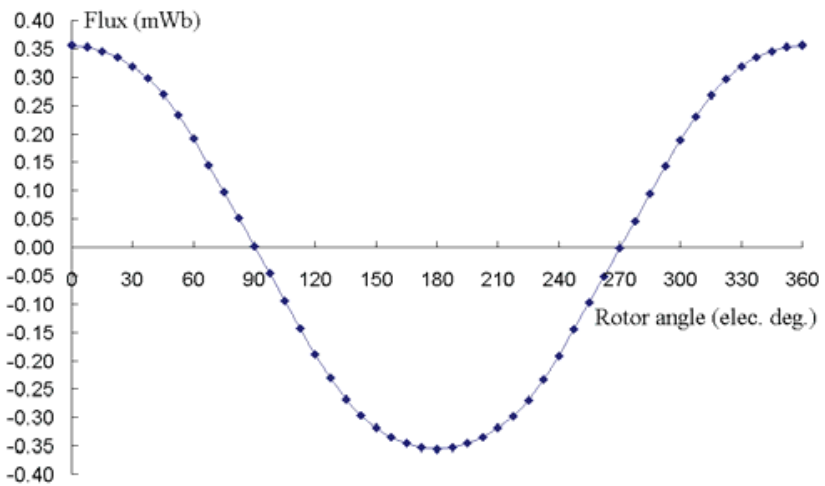

Fig. 5. Per-turn flux of a phase winding produced by rotor PMs

When the rotor rotates, a back-EMF is induced into the stator phase winding. The frequency of the back-EMF depends on the rotor speed while its waveform is determined by the phase winding flux-linkage waveform. According to Fig. 5, the back-EMF is close to sinusoidal (the differential of this waveform). The back-EMF constant can be computed:

$$
\mathrm{K}_{\mathrm{E}}=\frac{\mathrm{p}}{2} \mathrm{~N}_{\mathrm{s}} \frac{\varphi_{\max }}{\sqrt{2}}
$$

where $p=12$ is the number of poles, $N_{s}=256$ the number of turns of a stator phase winding, and the peak phase winding flux-linkage $\varphi_{\max }=0.354 \mathrm{mWb}$. The EMF constant can then be calculated to be $0.385 \mathrm{Vs} / \mathrm{rad}$.

From the no-load magnetic field solutions, the cogging torque curve can be obtained by using the virtual work method or the Maxwell stress tensor method.

The winding inductance is one of the major parameters affecting the motor performance. The behavior of an electrical circuit is determined by the incremental inductance rather than the apparent inductance [28]. Fig. 6 plots the selfinductance of a phase winding using a modified incremental energy method [29]. The incremental inductance is computed using the following steps:

(1) For a given rotor position, perform a non-linear 
analysis which accounts for the saturation due to the rotor PMs (assuming the magnetic field produced by the PMs is dominant);

(2) Save the incremental permeability in each element;

(3) "Switch off" the rotor PMs, and perform a linear field analysis with the saved permeabilities under a perturbed current excitation;

(4) Calculate the value of the incremental magnetic coenergy for the current excitation;

(5) Finally, the self incremental inductance can be computed from

$$
\mathrm{L}_{\mathrm{inc}} \approx \frac{2 \Delta \mathrm{W}_{\mathrm{c}}}{(\Delta \mathrm{i})^{2}}
$$

The apparent self inductance can also be computed by the above method if, in step 2, the apparent permeability is saved. The mutual inductance between phase windings can be considered as zero if each stack is assumed to be magnetically independent. It can be seen that unlike conventional machines, claw pole SMC motors have large inductance variation due to their saliency, which may affect the dynamic performance [30].

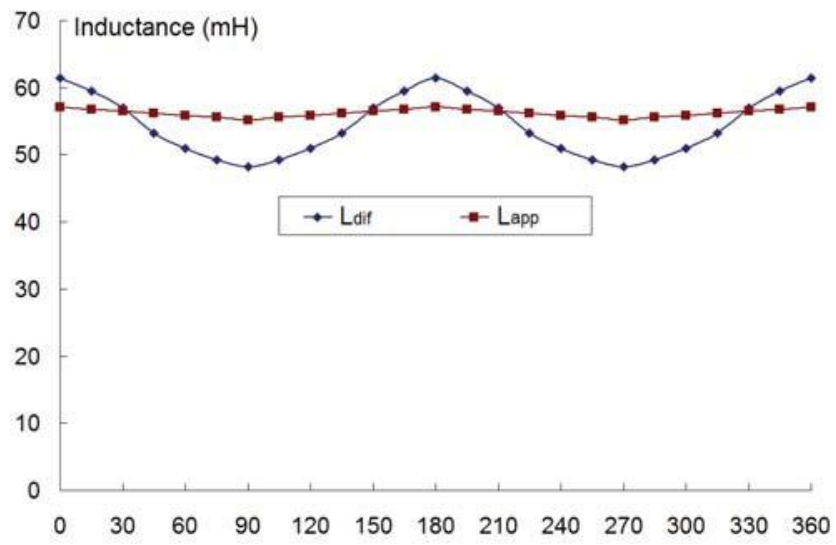

Fig. 6. Incremental and apparent inductances of a phase winding

The SMC machine is different from a conventional machine where the copper loss dominates; the core loss and copper loss in an SMC machine are more comparable. Therefore, it is very important to accurately predict the core loss. This can be done by taking into account the waveform of the flux density locus in each element of the core when the rotor rotates [31]. Due to the large value, the core loss variation can be significant across the dynamic performance simulation range. In this paper, the variation is obtained using a magnetic field time-stepping finite element analysis (FEA) and an improved three-term formula [32] where

$$
\begin{aligned}
& \mathrm{P}_{\mathrm{fe}}=\left\{\mathrm{H}_{\mathrm{j}} \frac{\mathrm{dB}}{\mathrm{dt}} \dot{j}^{2}\right\}^{\underline{\beta}}+\frac{\mathrm{k}}{2 \pi^{2}}{ }^{\mathrm{z}}(\underset{\mathrm{dt}}{\mathrm{dB}})+\frac{\mathrm{k}}{\mathrm{C}}\left\{{ }^{\mathrm{z}}\left(\begin{array}{c}
\mathrm{dB} \\
\mathrm{dt}
\end{array}\right\}^{3}\right. \\
& \begin{array}{llllll}
j & \beta_{2} \quad \mathrm{c} & \mathrm{j} & \mathrm{j} 2 & -
\end{array}
\end{aligned}
$$

The coefficients $\beta, k_{c}, k_{e}$ and $C_{e}$ are obtained by curve fitting the measurements on to a cubic SMC sample by using a 3-D magnetic property tester [33].

The time stepping FEA and core loss computation are carried out on an elemental basis. The total core loss is obtained by summing the core loss in each element. Fig. 7 plots the computed transient core loss against rotor angle.

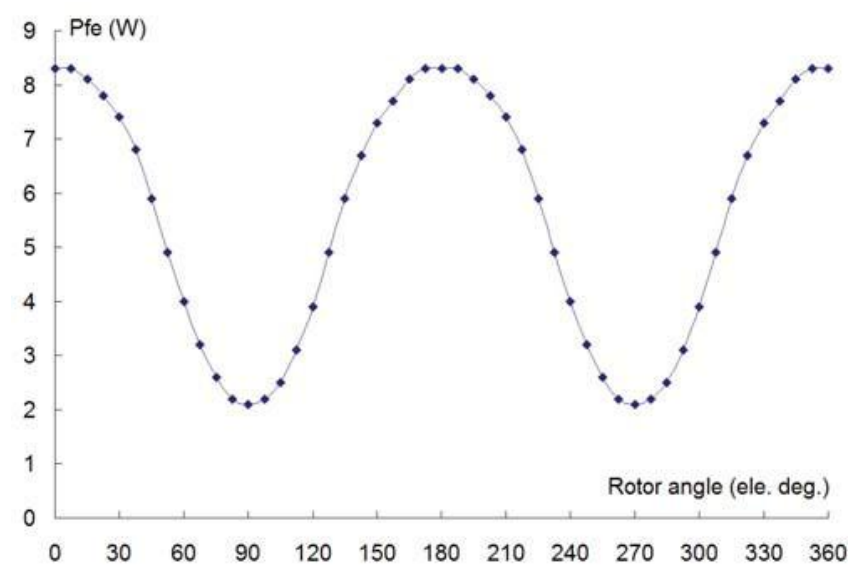

Fig. 7. Transient core loss

\section{B. Improved Phase Variable Model and Motor} Performance Prediction

An improved phase-variable model [34] is applied to analyze the performance of the motor when it is driven by a sensorless brushless DC (BLDC) controller (as developed at the University of Technology Sydney), which can produce a reasonably sinusoidal phase voltage waveform to match that of the motor back EMF. The electro-mechanical equations of the phase-variable model are described below where $\mathrm{L}_{\mathrm{jk}}$ is the apparent inductance (which is independent of the stator currents), and $\mathrm{L}_{\mathrm{jk}}^{\prime}$ the incremental inductance. All other parameters are used in their conventional meaning.

It should be noted that the mutual inductance for this motor is quite small since each phase stack is almost magnetically independent. The three phase windings are connected in star with a central point for experimental measurement. The electro-mechanical equations are:

$$
\begin{gathered}
v_{j}=r_{j} i_{j}+d \lambda_{j} / d t+e_{j}, j=a, b, c \\
\lambda_{j}=L_{j k}^{c} i_{k k} \\
\frac{d \lambda_{j}}{d t}={ }_{k=a}^{c} \frac{\partial \lambda_{j} d i_{k}}{\partial i_{k} d t}+\frac{\partial \lambda_{j} d \theta_{r}}{\partial \theta_{r} d t} \\
\left.=c L_{j k} i_{k} \omega_{r}\right) \\
=L_{k} d i \frac{d}{d t}+\frac{d L_{j}}{d \theta^{r}}
\end{gathered}
$$




$$
\begin{gathered}
T_{e m}=\left(e_{j=a}^{c} e_{j} i_{j}\right) / \omega_{r}+T_{c o g} \\
J \frac{d \omega_{r}}{d t}=T_{e m}-\frac{P_{f e}}{\omega_{r}}-T_{L}-\delta \omega_{r}, \frac{d \theta_{r}}{d t}=\omega_{r} \\
r_{j}=r_{k}, \quad L_{j k}=L_{k j}, \quad i_{j=a}^{c}=0 \quad(j, k=a, b, c)
\end{gathered}
$$

Suppose that the terminal potentials (voltages) of the starconnected three-phase phase windings are $\mathrm{U}_{\mathrm{a}}, \mathrm{U}_{\mathrm{b}}$ and $\mathrm{U}_{\mathrm{c}}$, respectively, then the central star point voltage $U_{N}$ can be calculated from

$$
\begin{aligned}
& \mathrm{v}_{\mathrm{j}}=\mathrm{U}_{\mathrm{j}}-\mathrm{U}_{\mathrm{N}},(\mathrm{j}=\mathrm{a}, \mathrm{b}, \mathrm{c}) \\
& \mathrm{U}_{\mathrm{N}}=\mathrm{j}_{\mathrm{j}=\mathrm{a}}^{\mathrm{c}}\left(\mathrm{U}_{\mathrm{j}}-\mathrm{v}_{\mathrm{j}}\right) / 3
\end{aligned}
$$

By substituting (6) to (8) into (13), and with due consideration of (11), we have

$$
U_{N}=\frac{1}{3}{ }_{j=a}^{c} U_{j}-{ }_{k=a}^{c} I_{j k}^{\prime} \frac{d i_{k}}{d t}+\frac{d L_{j k}}{d \theta_{r}} i_{k} \omega_{r} I-e_{j}
$$

The values of $U_{j}(j=a, b, c)$ are decided by the switching states of the inverter, which represent the PWM states that are used to control the 3-phase winding currents. Under BLDC control, there are only two phase windings that are energized at any moment, e.g., the current flows into phase $b$ and then out of phase c via the central point, and phase a is nonenergized (120 degree conduction). $U_{N}$ and $U_{a}$ can be obtained from

$$
\begin{gathered}
U_{N}=\frac{1}{2}{ }_{j=b}^{c} I U_{j}-L_{j j}^{\prime} \frac{d i_{j}}{d t}-\frac{d L_{j j}}{d \theta_{r}} i_{j} \omega_{r}-e_{j} I \\
U_{a}=U_{N}+{ }_{j=a}^{c} L_{j a}^{\prime} \frac{d i_{a}}{d t}+e_{a}+{ }_{k=b}^{c} I L_{a k}^{\prime} \frac{d i_{k}}{d t}+\frac{d L_{a k}}{d \theta_{r}} i_{k} \omega_{r} I
\end{gathered}
$$

When the phase current is not zero and the PWM is in the off state, $\mathrm{U}_{\mathrm{a}}$ is obtained from

$$
\mathrm{U}_{\mathrm{a}}=\mathrm{U}_{\text {bus }} \text { if } \mathrm{I}_{\mathrm{a}}>0, \mathrm{U}_{\mathrm{a}}=0 \text { if } \mathrm{I}_{\mathrm{a}}<0
$$

where $\mathrm{U}_{\text {bus }}$ is the potential of the power bus line.

Using (15)-(17), we can derive the potentials of the input ports and the central star point of the three phase windings, and hence the three phase voltages.

By defining the voltage

$$
\mathrm{v}_{\mathrm{am}}=\mathrm{k}=\mathrm{b}_{\mathrm{ak}}^{\mathrm{c}} \frac{\mathrm{di}_{\mathrm{k}}}{\mathrm{dt}}+{ }_{\mathrm{k}=\mathrm{a}}^{\mathrm{c}} \frac{\mathrm{dL}_{\mathrm{ak}}}{\mathrm{d} \theta_{\mathrm{r}}} \mathrm{i}_{\mathrm{k}} \mathrm{w}_{\mathrm{r}}
$$

and referring to (8), we get

$$
\begin{gathered}
v_{a}=\left(r_{a} i_{a}+L_{a a}^{\prime} \frac{d i_{a}}{d t}\right)+v_{a m}+e_{a} \\
v_{a}^{\prime}=v_{a}-v_{a m}=\left(r_{a} i_{a}+L_{a a}^{\prime} \frac{d i_{a}}{d t}\right)+e_{a}
\end{gathered}
$$

Similarly, $\mathrm{v}_{\mathrm{bm}}, \mathrm{v}_{\mathrm{b}}^{\prime}, \mathrm{v}_{\mathrm{cm}}$ and $\mathrm{v}_{\mathrm{c}}^{\prime}$ can be defined.

Based on the above equations, an improved phase-variable model can be developed in Simulink for simulating both the steady-state and dynamic performances of the motor, as illustrated in Fig. 8.

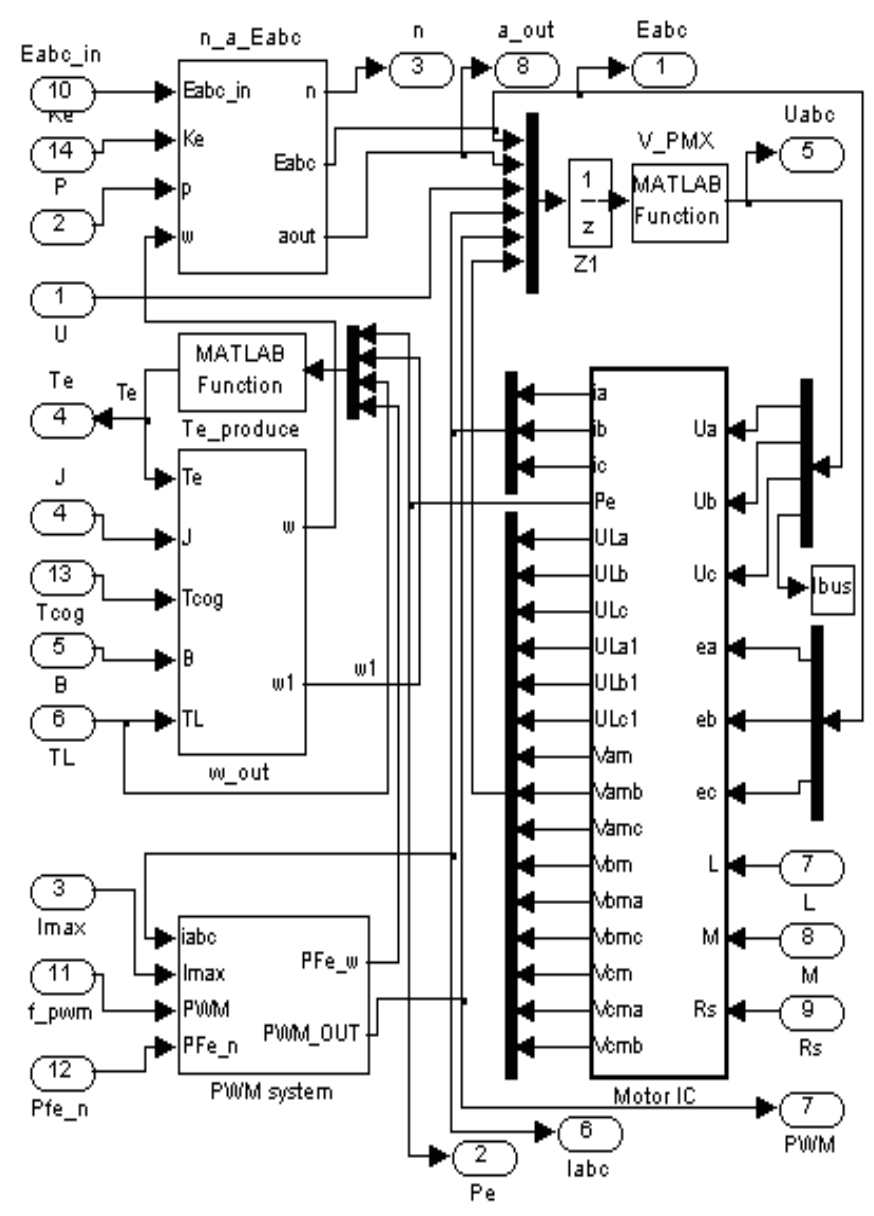

Fig. 8. Simulink implementation of an improved phase-variable model

Compared to the magnetic field FEA, the improved phasevariable model can predict the motor using a much shorter time but with the same level of accuracy. The dependence of key parameters on time or rotor angle has been previously obtained using a series of time-stepping FEA solutions. The variations of parameters against rotor position are stored in a lookup table and will be retrieved during the performance simulation.

From Fig. 8, key motor performance characteristics can be 
predicted. For example, Fig. 9 illustrates the simulated speed curve from start-up, showing that the motor can accelerate smoothly to the rated speed of $3000 \mathrm{rpm}$ at the rated torque of 0.2 Nm. Fig. 10 shows the simulated steady-state electromagnetic torque with ripple, which is caused by the cogging torque, transient core loss torque and phase current switching. Fig. 11 plots the simulated applied voltage, backEMF and phase current.

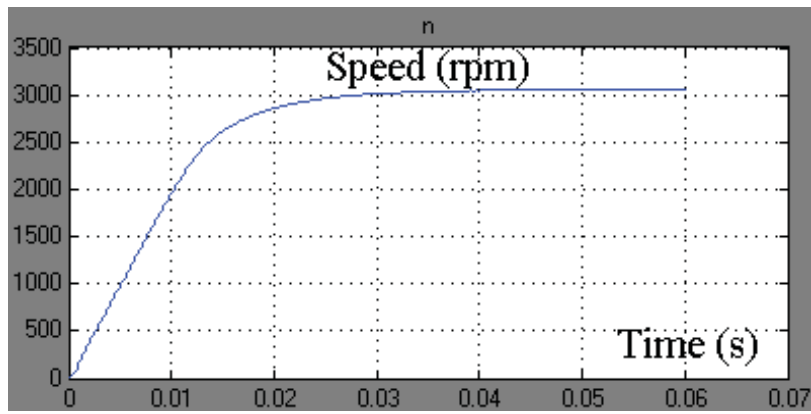

Fig. 9. Simulated speed curve from startup to steady state

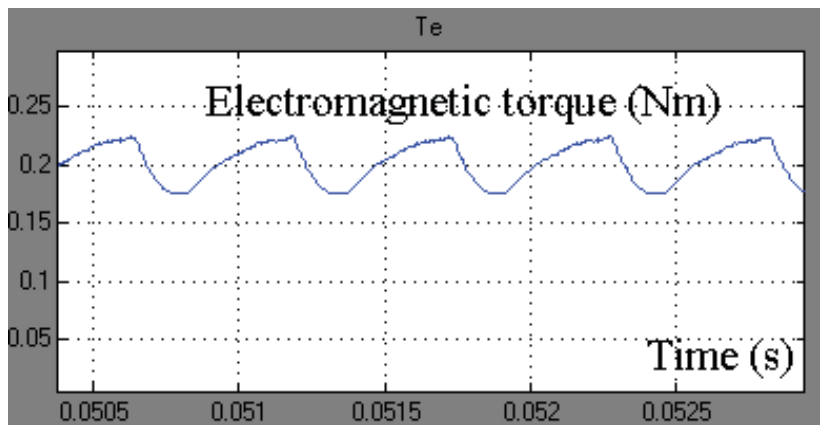

Fig. 10. Simulated steady electromagnetic torque

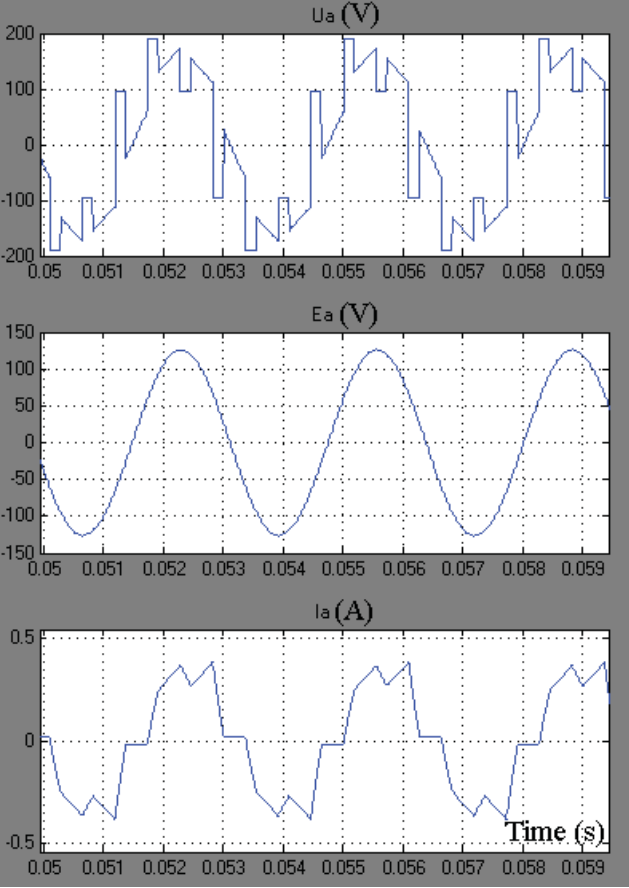

Fig. 11. Simulated phase voltage, back EMF and current

\section{EXPERIMENTAL RESULTS}

The motor parameter calculations have been verified by measurements on the prototype. For example, the back-EMF waveform (open-circuit voltage) was recorded on a CRO when the rotor was rotated. From the approximately sinusoidal waveform, the peak-to-peak EMF was found to be $46.5 \mathrm{~V}$ at $39.7 \mathrm{~Hz}$. It can be deduced that the per-turn winding flux-linkage (with the rotor PMs) is $0.364 \mathrm{mWb}$, which is very close to the calculation. With the voltagecurrent method, the equivalent phase winding inductance was found to be $50.9 \mathrm{mH}$, which is close to the average value of $54.1 \mathrm{mH}$ (differential) or $56.2 \mathrm{mH}$ (apparent) in Fig. 6. The mutual inductance was measured as only about $5 \%$ the self inductance.

Fig. 12 illustrates the experimental setup for measuring the motor performance. The SMC motor prototype is on the right and a dynamo load cell is on the left. A torque transducer is mounted between the motor and the load for measuring the shaft torque and speed. Fig. 13 plots the measured mechanical characteristics, i.e., the motor speed against applied DC link voltage of the inverter with different loads. The motor can successfully deliver a torque of $0.2 \mathrm{Nm}$ at $3000 \mathrm{rpm}$. 


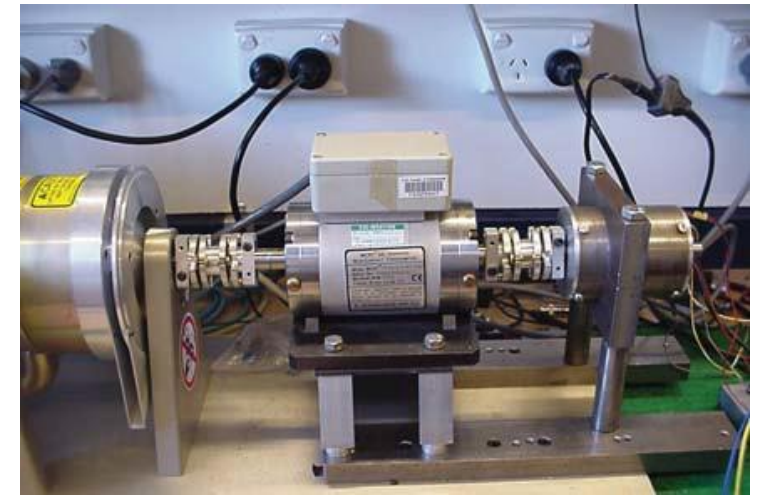

Fig. 12. Experimental setup

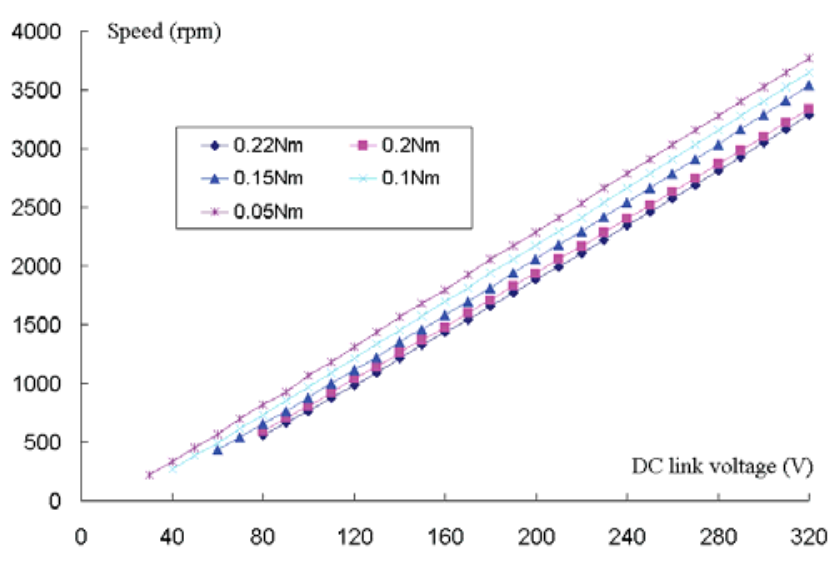

Fig. 13. Speed vs. DC link voltage with constant torque

\section{CONCLUSION}

This paper presents the development of a three-phase permanent magnet motor with a molded low density soft magnetic composite (SMC) stator for driving a dish washer pump. 3-D magnetic field finite element analyses were carried out and these accurately computed the key motor parameters such as winding flux-linkage, back-EMF, cogging torque, winding inductance and core loss. An improved phase-variable model was developed in Matlab/Simulink for analyzing the motor performance. In this model, the rotor position dependence of key parameters can be accounted for. The developed motor has been prototyped and tested, validating the design and analysis. It is anticipated that the molded low-density SMC core would be a cost-effective technique for mass production of SMC electrical machines.

\section{ACKNOWLEDGMENT}

The authors gratefully acknowledge the financial support of the Australian Research Council (Linkage Project Grant: LP0454306) which allowed this work to be carried out.

\section{REFERENCES}

[1] The latest development in soft magnetic composite technology, SMC Update, Reports of Höganäs AB, Sweden. (1997-2008). [Online]. Available at http://www.hoganas.com/.

[2] M. Persson, P. Jansson, A. G. Jack and B. C. Mecrow, "Soft magnetic composite materials - use for electrical machines," in Proc. $7^{\text {th }}$ IEE Conf. on Electrical Machines and Drives, Durham, England, Sept. 1995, pp. 242-246.

[3] F. Profumo, A. Tenconi, Z. Zhang and A. Cavagnino, "Novel axial flux interior PM synchronous motor realized with powdered soft magnetic materials," in Proc. 1998 IEEE Industry Application Society Annual Meeting, St. Louis, USA, Oct. 1998, pp.152-158.

[4] G. Cvetkovski, L. Petkovska, M. Cundev and S. Gair, "Improved design of a novel PM disk motor by using soft magnetic composite material," IEEE Trans. Magn., vol. 38, no. 5, pp. 3165-3167, Sept. 2002.

[5] M. A. Khan, Y. Chen, and P. Pillay, "Application of soft magnetic composites to PM wind generator design," in Proc. 2006 IEEE Power Engineering General Meeting, 4 pages.

[6] G. S. Liew, N. Ertugrul, W. L. Soong, and D. B. Gehlert, "Analysis and performance evaluation of an axial-field brushless PM machine utilising soft magnetic composites," in Proc. IEEE Int. Electric Machines and Drives Conf., May 2007, pp. 153-158.

[7] A. G. Jack, B. C. Mecrow, C. P. Maddison and N. A. Wahab, "Claw pole armature permanent magnet machines exploiting soft iron powder metallurgy," in Proc. IEEE Int. Conf. on Electric Machines and Drives, Milwaukee, USA, May 1997, pp. MA1/5.1-5.3.

[8] J. Cros and P. Viarouge, "New structures of polyphase claw-pole machines," in Proc. IEEE $37^{\text {th }}$ Industry Applications Society Annual Meeting, Oct. 2002, pp. 2267-2274.

[9] R. Qu, G. B. Kliman, and R. Carl, "Split-phase claw-pole induction machines with soft magnetic composite cores," in Proc. IEEE $39^{\text {th }}$ Industry Applications Society Annual Meeting, Oct. 2004, pp. 25142519.

[10] Y. G. Guo, J. G. Zhu, P. A. Watterson, and W. Wu, "Development of a claw pole permanent magnet motor with soft magnetic composite stator," Australian Journal of Electrical \& Electronic Engineering, vol. 2 , no. 1 , pp. 21-30, 2005.

[11] B. C. Mecrow, A. G. Jack and C. P. Maddison, "Permanent magnet machines for high torque, low speed applications," in Proc. Int. Conf. on Electrical Machines, Vigo, Spain, Sept. 1996, pp. 461-466.

[12] R. Blissenbach and G. Henneberger, "New design of a soft magnetic composite transverse flux machine with special attention on the loss mechanisms," in Proc. $4^{\text {th }}$ Int. Symp. on Advanced Electromotion, Bologna, Italy, June 2001.

[13] Y. G. Guo, J. G. Zhu, P. A. Watterson, and W. Wu, "Development of a permanent magnet transverse flux motor with soft magnetic composite core," IEEE Trans. on Energy Conversion, vol. 21, no. 2, pp. 426-434, June 2006.

[14] A. G. Jack, B. C. Mecrow and C. P. Maddison, "Combined radial and axial permanent magnet motors using soft magnetic composites," in Proc. $9^{\text {th }}$ Int. Conf. on Electrical Machines and Drives, Canterbury, UK, Sept. 1999, pp.25-29.

[15] A. G. Jack, B. C. Mecrow, P. G. Dickison, D. Stephenson, J. S. Burdess, N. Fawcett and J. T. Evans, "Permanent magnet machines with powdered iron cores and pre-pressed winding," IEEE Trans. on Industry Applications, vol. 36, no. 4, pp. 1077-1082, 2000.

[16] J. Cros, P. Viarouge and C. Gelinas, "Design of PM brushless motors using iron-resin composites for automotive applications," in Proc. IEEE $33^{\text {rd }}$ Industry Application Society Annual Meeting, St. Louis, USA, Oct. 1998, pp. 5-11.

[17] J. Cros, P. Viarouge and A. Halila, "Brush DC motors with concentrated windings and soft magnetic composites armatures," in Proc. IEEE $36^{\text {th }}$ Industry Application Society Annual Meeting, Chicago, USA, 2001, pp. 2549-2556.

[18] A. G. Jack, B. C. Mecrow, P. Dickson, P. Jansson and L. Hultman, "Design and testing of a universal motor using a soft magnetic composite stator," in Proc. IEEE Industry Applications Society Annual Conference, Rome, Italy, Oct. 2000, pp. 46-50.

[19] J. Cros, P. Viarouge, Y. Chalifour and J. Figueroa, "A new structure of universal motor using soft magnetic composites," in Proc. IEEE $36^{\text {th }}$ 
Industry Application Society Annual Meeting, Chicago, USA, 2001, pp. 75-81.

[20] T. Fukuda and M. Morimoto, "Load characteristics of induction motor made of Soft Magnetic Composite (SMC)", in Proc. 2008 Int. Conf. on Electrical Machines and Sys., Wuhan, China, Oct. 2008, pp. 53-56.

[21] K. Vijayakumar, R. Karthikeyan, G.K. Sathishkumar, and R. Arumugam, "Two dimensional magnetic and thermal analysis of high speed switched reluctance motor using soft magnetic composite material," in Proc. TENCON - IEEE Region 10 Conf., Nov. 2008, pp. $1-5$.

[22] A. G. Jack, "Experience with the use of soft magnetic composites in electrical machines," in Proc. Int. Conf. on Electrical Machines, Istanbul, Turkey, 1998, pp. 1441-1448.

[23] Y. G. Guo, J. G. Zhu, P. A. Watterson, and W. Wu, "Comparative study of 3-D flux electrical machines with soft magnetic composite core," IEEE Trans. on Industry Applications, vol. 39, no. 6, pp. 16961703, Nov. 2003.

[24] W. Ouyang and T. A. Lipo, "Multiphase modular permanent magnet drive system design and realization," in Proc. IEEE Int. Electrical Machines and Drives Conf., 2007, pp. 787-792.

[25] G. S. Liew, E. C. Y. Tsang, N. Ertugrul, W. L. Soong, D. Atkinson, and D. B. Gehlert, "Analysis of a segmented brushless PM machine utilising soft magnetic composites," in Proc. $33^{\text {rd }}$ Annual Conf. of IEEE Industrial Electronics Society, 2007, 1268-1273.

[26] Y. G. Guo, J. G. Zhu, and D. G. Dorrell, "Design and analysis of a claw pole PM motor with molded SMC core," IEEE Trans. Magn., 2009, in press.

[27] "Soft Magnetic Composites from Höganäs Metal Powders SOMALOY TM 500”, Höganäs Manual, 1997.
[28] M. Gyimesi and D. Ostergaard, "Inductance computation by incremental finite element analysis," IEEE Trans. Magn., vol. 35, pp. 1119-1122, 1999

[29] Y. G. Guo, J. G. Zhu, and H. Y. Lu, "Accurate determination of parameters of a claw pole motor with SMC stator core by finite element magnetic field analysis," IEE Proceedings - Electric Power Application, vol. 153, no. 4, pp. 568-574, July 2006.

[30] Y. G. Guo, J. G. Zhu, Z. W. Lin, H. Y. Lu, X. L. Wang, and J. X. Chen, "Influence of inductance variation on the performance of a PM claw pole SMC motor," Journal of Applied Physics, vol. 103, no. 7, pp. 07F118-1-3, 1 Apr. 2008

[31] Y. G. Guo, J. G. Zhu, J. J. Zhong, and W. Wu, "Core losses in claw pole permanent magnet machines with soft magnetic composite stators," IEEE Trans. Magn., vol. 39, no. 5, pp. 3199-3201, Sept. 2003.

[32] D. Lin, P. Zhou, W. N. Fu, Z. Badics, and Z. J. Cendes, "A dynamic core loss model for soft ferromagnetic and power ferrite materials in transient finite element analysis," IEEE Trans. Magn., vol. 40, no. 2, pp. 1318-1321, Mar. 2004.

[33] Y. G. Guo, J. G. Zhu, Z. W. Lin, and J. J. Zhong, "Measurement and modeling of core losses of soft magnetic composites under 3D magnetic excitations in rotating motors," IEEE Trans. Magn., vol. 41, no. 10 , pp. 3925-3927, Oct. 2005

[34] J. X. Chen, Y. G. Guo, J. G. Zhu, and J. X. Jin, "Performance analysis of a surface mounted permanent magnet brushless DC motor using an improved phase variable model," in Proc. 42 $2^{\text {nd }}$ IEEE Industry Applications Society Annual Conf., New Orleans, USA, Sept. 2007, pp. 2169-2174. 